\title{
Produção Animal e Retorno Econômico em Misturas de Gramíneas Anuais de Estação Fria
}

\author{
João Restle ${ }^{1}$, Cledson Roso², André B. Soares²
}

\begin{abstract}
RESUMO - O desempenho e a produtividade animal em misturas de gramíneas anuais de estação fria sob pastejo contínuo foram avaliados. As misturas MTA - Triticale (X Triticosecale) + azevém (Lolium multiflorum), MAA - Aveia preta (Avena strigosa)+ azevém, MTAA - Triticale + aveia preta + azevém foram usadas. A semeadura a lanço foi realizada em 21/04/95, sendo adubada com $200 \mathrm{~kg} / \mathrm{ha}$ (05-30-15), sendo a adubação de cobertura de $175 \mathrm{~kg} /$ ha de nitrogênio. O início do pastejo ocorreu em 10/06/95, estendendo-se até 14/11/95. O ganho de peso médio diário foi similar entre as misturas, sendo de 693, 685 e 665 g, para MTA, MAA e MTAA, respectivamente. A carga animal média foi superior na mistura MTA em relação às demais, sendo de 1210,1055 e $1116 \mathrm{~kg}$ de PV/ha. A mistura MTA apresentou o maior ganho de peso vivo/ha (650,7 kg/ha), seguida pela MTAA $(592,4 \mathrm{~kg} / \mathrm{ha})$ e MAA $(568,8 \mathrm{~kg} / \mathrm{ha})$. O custo/ha foi superior na MTA (R\$320,42), seguido pela MTAA (R\$316,47) e MAA (R\$312,69); a receita líquida foi também superior na MTA (R\$ 167,60), seguida pela MTAA (R\$127,83) e MAA ( $\$ 113,91)$. A mistura de triticale mais azevém foi a mais indicada, pois apresentou o maior ganho de peso por unidade de área, resultando em maior retorno econômico.
\end{abstract}

Palavras-chave: aveia preta, azevém, carga animal, custo, eficiência de utilização da matéria seca, pastejo, receita líquida, triticale

\section{Animal Production and Economic Return in Mixtures of Annual Temperate Grasses}

\begin{abstract}
The animal performance and productivity in mixtures of annual temperate grasses under continuous grazing condition were evaluated. The mixtures MTR - Triticale (XTriticosecale Wittmack) plus ryegrass (Lolium multiflorum Lam.), MOR - Oat (Avena strigosa Schreb) plus ryegrass, MTOR - Triticale plus oat plus ryegrass, were used. The broadcasting sowing was realized at $04 / 21 / 95$, being fertilized with $200 \mathrm{~kg} / \mathrm{ha}$ (05-30-15), being the broadcasting fertilization of $175 \mathrm{~kg} / \mathrm{ha}$ of nitrogen. The beginning of the grazing occurred at $06 / 10 / 95$, and was extended until 11/14/95. The average daily weight gain was similar among the mixtures, being 693, 685 and $665 \mathrm{~g}$, for MTR, MOR and MTOR, respectively. The average stocking rate was superior in the MTR mixtures in relation to the others, being $1.210,1.055$ and $1.116 \mathrm{~kg}$ of LW/ha. The MTR mixture presented the highest live weight gain/ha (650.7 kg/ha), followed by MTOR (592.4 kg/ha) and MOR $(568.8 \mathrm{~kg} / \mathrm{ha})$. The cost/ha was superior in the MTR (R\$320,42), followed by MTOR (R \$ 316,47) and MOR (R\$312,69), the net income was also higher for MTR (R\$ 167,60), followed by MTOR (R\$127,83) and MOR (R\$113,91). The triticale plus ryegrass mixture was the most indicated because presented the higher weight gain per unit of area, resulting in higher economic return.
\end{abstract}

Key Words: oat, ryegrass, stocking rate, cost, dry matter utilization efficiency, grazing, net income, triticale

\section{Introdução}

A pecuária de corte passa por inúmeras dificuldades econômicas, necessitando aumentar a produtividade para tornar-se atividade viável e competitiva. A base da alimentação da pecuária de corte no Rio Grande do Sul é o campo nativo, que é composto principalmente por espécies estivais, apresentando elevada produção de forragem no verão, sendo que no outono-inverno, devido às baixas temperaturas e à pouca luminosidade, ocorre paralisação do crescimento e queda na qualidade da forragem nativa. A estacionalidade na produção de forragem acarreta falta de alimentos para os animais no outono-inverno, constituindo-se em uma das principais causas dos baixos índices produtivos da bovinocultura de corte. A utilização de gramíneas anuais de estação fria como pastagens é excelente alternativa em rotação com as culturas de verão para suprir o déficit alimentar sofrido pelo rebanho bovino, principalmente porque o Rio Grande do Sul apresenta aproximadamente 5 milhões de hectares cultivados com soja e milho, dos quais somente cerca de $12 \%$ são utilizados para o plantio do trigo, sendo que o restante da área é pouco aproveitado no inverno (IBGE, 1996). Resultados de pesquisa com aveia preta mais azevém têm demonstrado o elevado potencial de produção animal e de forragem destas espécies, na condição de pastejo (LUPATINI et al., 1998; RESTLE et al., 1993; e RESTLE et al., 1998). No entanto, a mistura tem

${ }^{1}$ Eng.-Agr ${ }^{\circ}$, Ph.D., Professor Titular, Bolsista do CNPq, Departamento de Zootecnia da UFSM, 97119 900, Santa Maria - RS.

2 Eng.-Agr ${ }^{\circ}$, Mestrando em Zootecnia, UFSM, Departamento de Zootecnia da UFSM, 97119 900, Santa Maria - RS. 
apresentado má distribuição na produção de forragem ao longo do período de utilização. Outras espécies de gramíneas anuais de estação fria são alternativas que podem ser usadas em misturas com o azevém; entre elas, o triticale tem demonstrado resultados promissores na produção de grãos e de forragem, destacando-se pela sua rusticidade e produtividade, conforme dados mostrados por BAIER (1989), apresentando grande potencial de adaptabilidade para as condições brasileiras (BAIER e NEDEL, 1985). No entanto, não existem informações sobre produção animal avaliando esta espécie em mistura com o azevém nas condições de pastejo .

O objetivo deste trabalho foi avaliar o desempenho e a produção animal, bem como o retorno econômico em misturas de gramíneas anuais de estação fria, para que as informações geradas possam ser utilizadas com a finalidade de melhorar os índices produtivos da pecuária de corte, visando tornar os sistemas de produção mais competitivos e lucrativos.

\section{Material e Métodos}

O experimento foi conduzido no Departamento de Zootecnia da Universidade Federal de Santa Maria, sobre um solo Podzólico Vermelho-Amarelo, situada na Depressão Central do Rio Grande do Sul, à altitude de $95 \mathrm{~m}$, latitude $29^{\circ} 43^{\prime}$ 'sul e longitude $53^{\circ} 42^{\prime}$ oeste. $\mathrm{O}$ clima da região é o cfa (subtropical úmido), conforme a classificação Köppen (MORENO, 1961).

Foram avaliadas as seguintes misturas de gramíneas anuais de estação fria sob pastejo: MTA Triticale (X Triticosecale Wittmack) cv. CEP.23 + azevém (Lolium multiflorum Lam.) cv. comum, MAA - Aveia preta (Avena strigosa Schreb) cv. comum + azevém, MTAA - Triticale + aveia preta + azevém. $\mathrm{O}$ delineamento experimental foi inteiramente casualizado, com três repetições (piquetes), sendo que cada piquete apresentava, em média, um hectare. Os dados foram submetidos à análise de variância (SAS, 1990), por intermédio do General Linear Models Procedure (GLM) e do teste da probabilidade da diferença (pdiff) a 5\% de significância, sendo usado o seguinte modelo matemático:

em que

$$
\mathrm{Y}_{\mathrm{ijk}}=\mathrm{M}+\mathrm{T}_{\mathrm{i}}+\mathrm{P}_{\mathrm{k}}+\mathrm{T}_{\mathrm{i}} \mathrm{P}_{\mathrm{k}}+\mathrm{E}_{\mathrm{ij}}
$$

$\mathrm{Y}_{\mathrm{ijk}}=$ variáveis dependentes;

$\mathrm{M}=$ média de todas as observações;

$\mathrm{T}_{\mathrm{i}}=$ efeito do tratamento $\mathrm{i}$;

$\mathrm{P}_{\mathrm{k}}=$ efeito do período $\mathrm{k}$;

$\mathrm{T}_{\mathrm{i}} * \mathrm{P}_{\mathrm{k}}=$ interação entre tratamento i e período $\mathrm{k}$; e
$E_{i j}=$ erro aleatório associado a cada observação j.

A área experimental vem sendo utilizada há vários anos com pastagens de gramíneas de ciclo anual, em experimentos com produção animal, recebendo adubações de base conforme as RECOMENDAÇÕES DE ADUBAÇÃO PARA O RIO GRANDE DO SUL (1989). O preparo do solo constou de gradagem pesada, por meio de grade aradora, e gradagem leve, por meio de grade niveladora. A adubação de manutenção foi realizada a lanço após a gradagem pesada, sendo utilizados $10 \mathrm{~kg}$ de $\mathrm{N}, 60 \mathrm{~kg}$ de $\mathrm{P}_{2} \mathrm{O}_{5}$ e $30 \mathrm{~kg}$ de $\mathrm{K}_{2} \mathrm{O}$ por ha. A semeadura, a lanço, foi realizada em 21 de abril de 1995, utilizando $30 \mathrm{~kg} / \mathrm{ha}$ de azevém com $150 \mathrm{~kg} / \mathrm{ha}$ de triticale ou $65 \mathrm{~kg} / \mathrm{ha}$ de aveia preta ou $75 \mathrm{~kg} / \mathrm{ha}$ e $33 \mathrm{~kg} / \mathrm{ha}$ de aveia preta, sendo as sementes incorporadas com grade de dentes. Na adubação nitrogenada de cobertura, foram aplicados $175 \mathrm{~kg} /$ ha de nitrogênio, na forma de uréia, parceladas em quatro aplicações; a primeira no perfilhamento (18/05) e as demais durante a utilização da pastagem, 26/07, 19/08 e 21/09/95.

Os resíduos da pastagem foram avaliados a cada 35 dias, aproximadamente, cortando-se, rente ao solo, dez amostras $\left(0,25 \mathrm{~m}^{2}\right)$ em cada piquete. A forragem proveniente destas amostras foi homogeneizada e retiradas duas amostras compostas, sendo que uma foi pesada e levada para estufa a $65^{\circ} \mathrm{C}$ por, no mínimo, 72 horas, para determinação do teor de matéria seca (MS) e da qualidade do resíduo. A outra amostra foi utilizada para a avaliação da composição botânica da pastagem, sendo separadas as espécies que compunham as misturas mais inços e material morto. Após a separação botânica, os componentes foram para a estufa a $65^{\circ} \mathrm{C}$ para se determinar o percentual em base na MS. Estas amostras, após a secagem, foram moídas em moinho tipo Wiley, com peneira de malha de $1 \mathrm{~mm}$ e guardadas em sacos plásticos para análises bromatológicas, em que foi determinado o teor de proteína bruta pelo método micro kjeldahl (AOAC, 1984) e a digestibilidade in vitro da matéria orgânica (DIVMO), por meio da determinação da digestibilidade in vitro da matéria seca e do teor de matéria orgânica (TILLEY e TERRY, 1963).

A taxa de acumulação de matéria seca foi avaliada em datas próximas às das avaliações dos resíduos, usando-se três gaiolas de exclusão ao pastejo por piquete, seguindo a técnica do triplo emparelhamento. A produção total de MS em $\mathrm{kg} /$ ha foi obtida pelo somatório das produções dos períodos (taxa de acumulação $\mathrm{x} \mathrm{n}^{\mathrm{o}}$ de dias) mais o resíduo inicial.

O método de pastejo foi o contínuo, com lotação variável, utilizando a técnica de "put-and-take" (MOTT 
e LUCAS, 1952). Foram utilizados três animais testers por piquete e um número variável de reguladores, conforme a necessidade de ajuste de carga, pertencentes aos grupos genéticos Charolês, Nelore e cruzas F1 com idade média inicial de 7 meses e peso médio inicial de $148 \mathrm{~kg}$. A oferta de forragem pretendida foi de $10 \%$ do peso vivo (PV).

Os animais foram pesados com jejum de seis horas, nas seguintes datas: 10/06 (início do pastejo), 15/07, 19/08, 23/09, 31/10 e 14/11/95 (final do pastejo). O controle de endo e ectoparasitas seguiu o calendário de Setor de Bovinocultura de Corte do Departamento de Zootecnia e as vacinações seguiram o calendário da Secretaria de Agricultura. Os animais tiveram livre acesso ao sal comum.

O ganho médio diário dos testers em cada período foi obtido pela diferença entre as pesagens do início e do final de cada período experimental, dividido pelo número de dias do período. A carga animal por período, expressa em $\mathrm{kg}$ de peso vivo/ha/dia, foi calculada pelo somatório do peso médio de cada animal multiplicado pelo número de dias que este permaneceu na pastagem, dividido pelo número de dias do período. O ganho de peso vivo/ha foi obtido multiplicando-se o número de animais médio $\mathrm{x}$ dia/ha pelo ganho médio dos testers. A eficiência de transformação da forragem em ganho de peso foi obtida diminuindo-se da produção total de MS o resíduo final e dividindo pelo ganho de peso vivo/ha. $\mathrm{Na}$ análise econômica foram utilizados os preços de mercado da época de realização do trabalho.

\section{Resultados e Discussão}

O resíduo da pastagem na média das avaliações foi semelhante entre as misturas, sendo de 1662, 1703 e $1672 \mathrm{~kg}$ de $\mathrm{MS} / \mathrm{ha}$, respectivamente, para MTA, MAA e MTAA (Tabela 1), tendo apresentado variação semelhante no decorrer do período de pastejo. Os resíduos foram inferiores aos relatados por MORAES (1991), na oferta de forragem que apresentou a melhor produtividade animal (10,2\%), e por RESTLE et al. (1998), que avaliaram categorias de bovinos de corte em aveia preta mais azevém no período de agosto a

Tabela 1 - Resíduo (kg de MS/ha) e porcentagem de matéria seca por avaliação e média na pastagem com misturas de gramíneas anuais de estação fria ${ }^{1,2}$

Table 1 - Residue ( $\mathrm{kg}$ of DM/ha) and percentage of dry matter per evaluation and average of annual temperate grasses mixtures

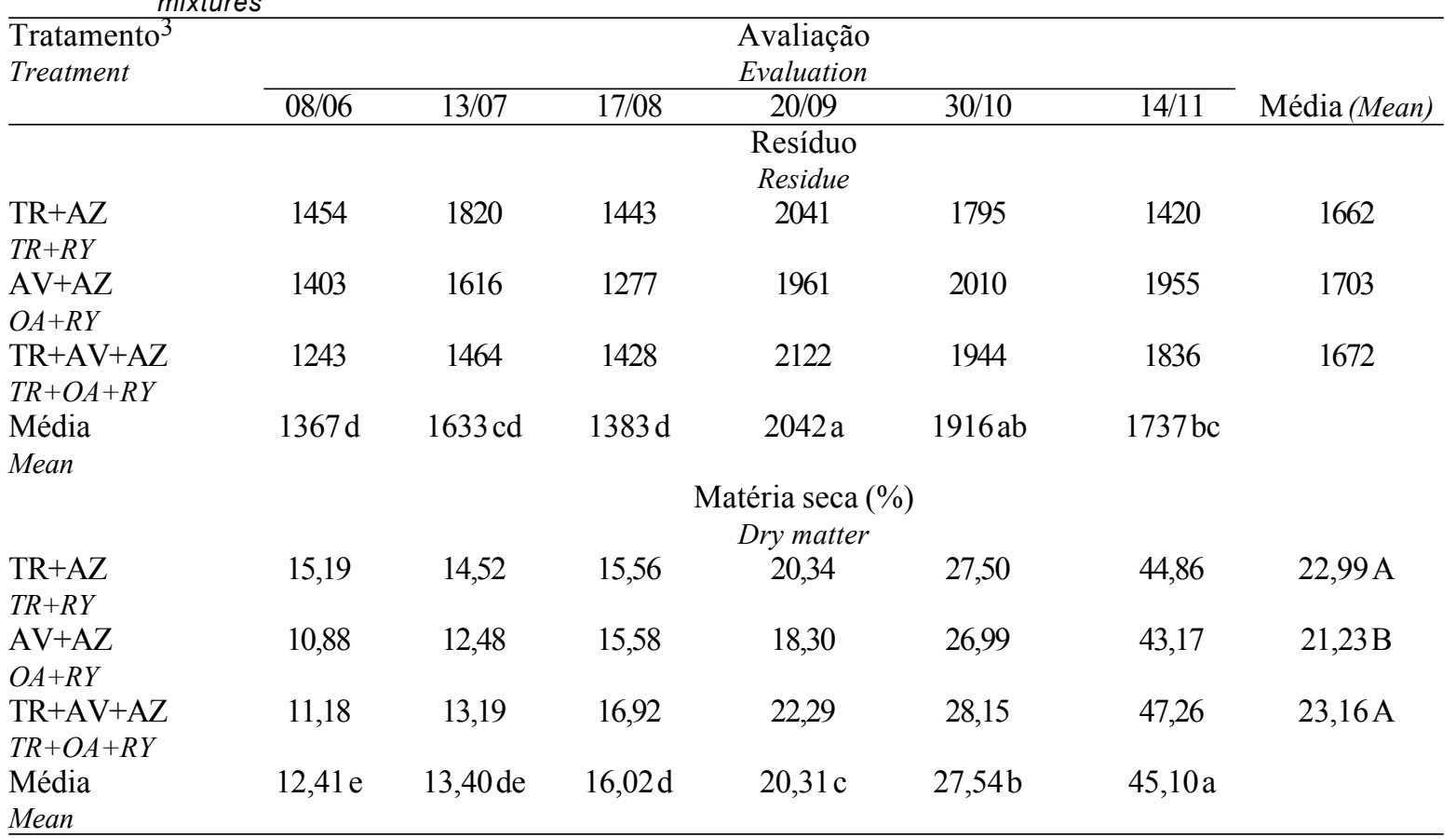

(Dia/mês, Day/month).

1 Médias, na linha, seguidas por letras diferentes $(a, b, c, d)$ diferem $(P<0,05)$.

${ }^{2}$ Médias, na coluna, seguidas por letras diferentes $(A, B)$ diferem $(P<0,05)$.

${ }^{3} \mathrm{TR}=$ triticale, $\mathrm{AV}=$ aveia, $\mathrm{AZ}=$ azevém.

${ }_{1}^{1}$ Means, within a row, followed by different letters $(a, b, c, d)$ differ $(P<.05)$.

${ }^{2}$ Means, within a column, followed by different letters $(A, B)$ differ $(P<.05)$.

${ }^{3} T R=$ triticale, $O A=$ oat, $R Y=$ ryegrass. 
meados de novembro, e superiores aos obtidos por CANTO et al. (1997), que trabalharam com a mistura de aveia preta e azevém mais ervilhaca ou nitrogênio.

No início do pastejo (10/06), os valores foram inferiores às demais avaliações, próximo a $1400 \mathrm{~kg}$ de $\mathrm{MS} /$ ha. Neste estádio de desenvolvimento ocorre grande acúmulo de forragem verde, favorecendo o acamamento inicial e rápida elevação do meristema apical. O manejo correto do resíduo inicial, ou seja, o momento de começar o pastejo e a carga animal a ser utilizada, é fator determinante na produção futura da pastagem, devendo-se evitar o pastejo precoce, quando ainda não ocorreu enraizamento suficiente para evitar o arranquio de plantas e acúmulo suficiente de carboidratos que permita bom rebrote, nem o pastejo muito tardio, pois favorecerá o acamamento e a elevação do meristema apical, sendo facilmente eliminado pelo pastejo. O resíduo no período de 08/06 a 17/08 foi menor na MAA em relação ao MTA, mesmo a pastagem tendo apresentado maior produção de forragem (Tabela 2) e tendo suportado menor carga animal (Tabela 5), o que, provavelmente, ocorreu devido à maior quantidade de forragem perdida pelo pisoteio, pois as plantas de aveia apresentaram colmos mais fracos em relação ao triticale, facilitando o acamamento.

Na Tabela 1, também encontram-se os valores da percentagem de MS dos resíduos, em que se observam menor teor de MS na mistura aveia preta mais azevém em relação às demais e aumento significativo com o passar do período de utilização das pastagens.

A digestibilidade in vitro da matéria orgânica (Tabela 3), em média, foi semelhante entre as misturas, sendo superiores às encontradas por RESTLE et al. (1998) e inferiores às obtidas por QUADROS e MARASCHIN (1987), CANTO et al. (1997), sen- do que esses autores trabalharam com misturas de gramíneas e legumiosas.

$\mathrm{O}$ teor de proteína bruta (PB) encontra-se na Tabela 3. Verificam-se elevados valores na maioria das avaliações, sendo que a mistura aveia preta mais azevém, em média, apresentou maior teor de PB em relação às demais misturas. Os valores médios são semelhantes aos obtidos por RESTLE et al. (1998), que trabalharam com aveia preta mais azevém, e superiores aos valores obtidos por QUADROS e MARASCHIN (1987), que trabalharam com misturas de gramíneas e legumiosas. Analisando os valores médios de cada período, observa-se que houve aumento gradual no teor de matéria seca do resíduo e queda nos valores de DIVMO e da PB (Tabela 3) com o avanço nos estádios de desenvolvimento das plantas.

O GMD (Tabela 4), na média do período experimental, foi semelhante entre as misturas, sendo de 693, 685 e 665 g para MTA, MAA e MTAA, respectivamente, pois o manejo da pastagem proporcionou disponibilidade de forragem semelhante e, provavelmente, a dieta selecionada apresentou qualidade semelhante entre as misturas. Os ganhos obtidos podem ser considerados bons, caso se considerem a categoria animal utilizada e o longo período de utilização da pastagem, sendo que o desempenho animal está diretamente associado com a quantidade de MS consumida e com a qualidade da pastagem (BLASER, 1990). Estes resultados são inferiores aos encontrados por QUADROS e MARASCHIN (1987), usando novilhos de 6 a 12 meses de idade em consorciações de gramíneas e leguminosas, e RESTLE et al. (1993, 1998), utilizando terneiros com idade média de dez meses em aveia preta mais azevém.

Os menores GMD foram registrados nos perío-

Tabela 2 - Produção de forragem (kg de MS/ha) da pastagem com misturas de gramíneas anuais de estação fria ${ }^{1}$ Table 2 - Forage production ( $\mathrm{kg}$ of DM/ha) of pasture of annual temperate grasses mixtures

\begin{tabular}{|c|c|c|c|c|c|c|c|}
\hline \multirow{2}{*}{$\begin{array}{l}\text { Tratamento }^{2} \\
\text { Treatment }\end{array}$} & \multicolumn{6}{|c|}{$\begin{array}{l}\text { Período } \\
\text { Period }\end{array}$} & \\
\hline & $21 / 04$ a 30/06 & $01 / 06 a 31 / 07$ & $01 / 08 \mathrm{a} 31 / 08$ & 01/09a 30/09 & $01 / 10 \mathrm{a} 31 / 10$ & $01 / 11$ a $14 / 11$ & \\
\hline $\begin{array}{l}\mathrm{TR}+\mathrm{AZ} \\
T R+R Y\end{array}$ & 2766 & 1668 & 1565 & 1554 & 1618 & 0525 & $09696 \mathrm{~A}$ \\
\hline $\begin{array}{l}\mathrm{AV}+\mathrm{AZ} \\
O A+R Y\end{array}$ & 2798 & 1761 & 1581 & 1632 & 1795 & 0706 & $10273 \mathrm{~A}$ \\
\hline $\begin{array}{l}\mathrm{TR}+\mathrm{AV}+\mathrm{AZ} \\
T R+O A+R Y\end{array}$ & 2440 & 1513 & 1286 & 1197 & 1193 & 0412 & 08041B \\
\hline $\begin{array}{l}\text { (Dia/mês, Day } \\
{ }^{1} \text { Médias, na } \\
2 \text { TR = triticale } \\
1 \text { Means, within } \\
2 \text { TR = triticale, }\end{array}$ & $\begin{array}{l}\text { th). } \\
\text { a, seguidas po } \\
=\text { aveia, } A Z= \\
\text { umn, followed by } \\
\text { oat, } R Y=\text { ryegra }\end{array}$ & $\begin{array}{l}\text { tras diferente } \\
\text { evém. } \\
\text { ferent letters }(A\end{array}$ & $\begin{array}{l}\text { A, B) diferem ( } \\
\text { differ }(P<.05)\end{array}$ & $=0,05)$. & & & \\
\hline
\end{tabular}


Rev. bras. zootec.

Tabela 3 - Digestibilidade in vitro da matéria orgânica e teor de proteína bruta dos resíduos de acordo com a avaliação e a média do período experimental da pastagem com misturas de gramíneas anuais de estação fria ${ }^{1,2}$

Table 3 - In vitro organic matter disappearance and crude protein content of the residuals according to the evaluation and the average of the experimental period of pastures of annual temperate grasses

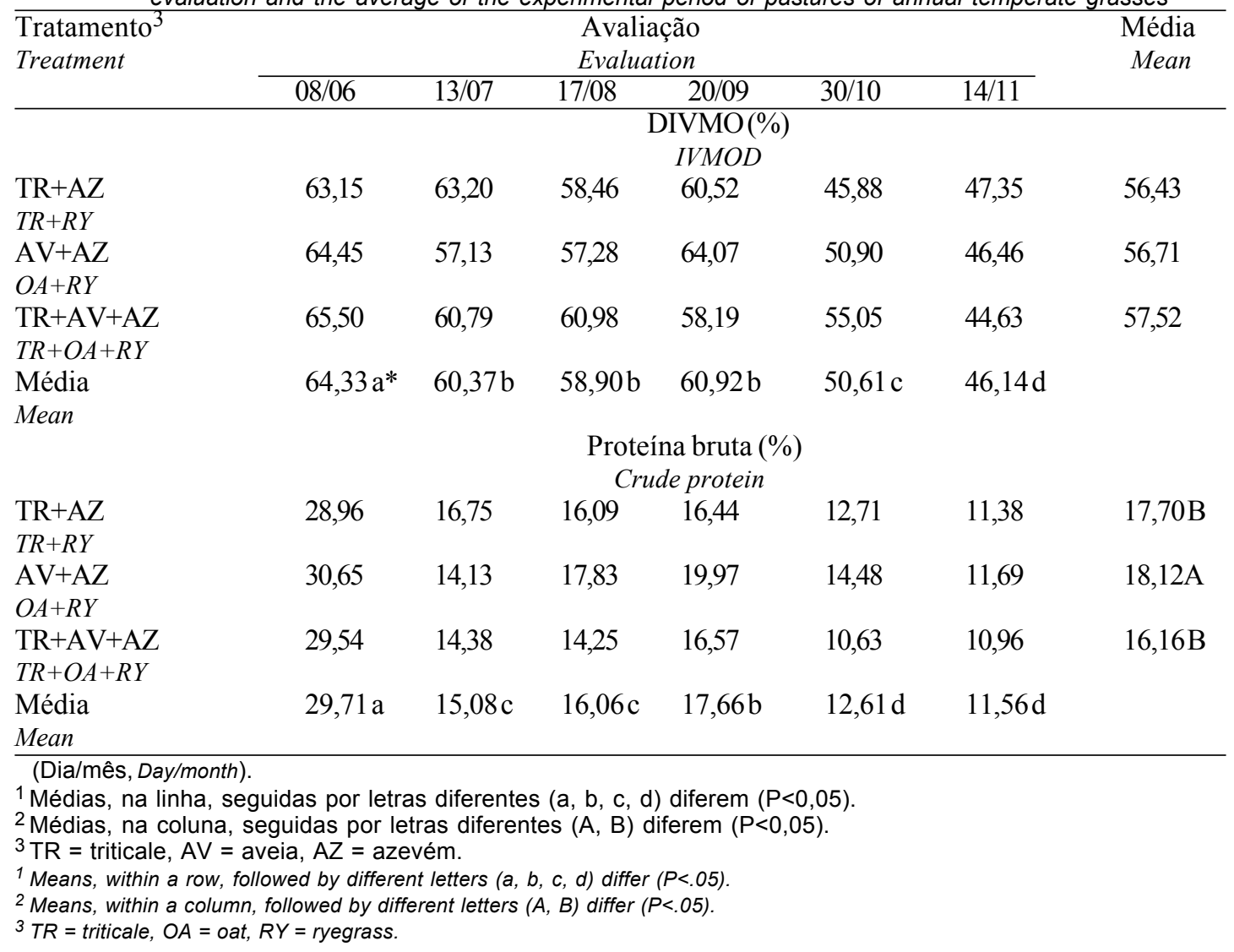

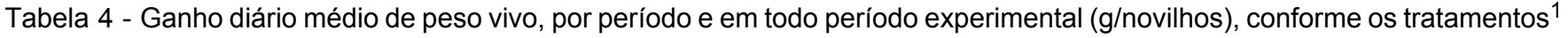
Table 4 - Average daily live weight gain, per period and over the experimental period ( $\mathrm{g} / \mathrm{steer}$ ), according to the treatments

\begin{tabular}{|c|c|c|c|c|c|c|}
\hline \multirow[t]{2}{*}{$\begin{array}{l}\text { Tratamento }^{2} \\
\text { Treatment }\end{array}$} & \multicolumn{5}{|c|}{$\begin{array}{c}\text { Período } \\
\text { Period }\end{array}$} & \multirow[t]{2}{*}{$\begin{array}{l}\text { Média geral } \\
\text { Great mean }\end{array}$} \\
\hline & $10 / 06$ a $15 / 07$ & $15 / 07$ a 19/08 & 19/08a 23/09 & $23 / 09$ a $31 / 10$ & $31 / 10$ a $14 / 11$ & \\
\hline $\mathrm{TR}+\mathrm{AZ}$ & 489 & 590 & 832 & 816 & 778 & 693 \\
\hline$T R+R Y$ & & & & & & \\
\hline $\begin{array}{l}\mathrm{AV}+\mathrm{AZ} \\
O A+R Y\end{array}$ & 654 & 403 & 698 & 968 & 667 & 685 \\
\hline $\begin{array}{l}\mathrm{TR}+\mathrm{AV}+\mathrm{AZ} \\
T R+O A+R Y\end{array}$ & 635 & 435 & 752 & 784 & 778 & 665 \\
\hline $\begin{array}{l}\text { Média } \\
\text { Mean }\end{array}$ & $593 c$ & $476 \mathrm{~d}$ & $761 \mathrm{a}$ & $856 a$ & $741 \mathrm{~b}$ & \\
\hline
\end{tabular}

(Dia/mês, Day/month).

1 Médias, na linha, seguidas por letras diferentes $(a, b, c, d)$ diferem $(P<0,05)$.

$2 \mathrm{TR}=$ triticale, $\mathrm{AV}=$ aveia, $\mathrm{AZ}=$ azevém.

1 Means, within a row, followed by different letters $(a, b, c, d)$ differ $(P<.05)$.

${ }^{2} T R=$ triticale, $O A=$ oat,$R Y=$ ryegrass. 
dos iniciais do pastejo, sendo de 593 e 476 g/an./dia, respectivamente, para o primeiro e segundo período, mesmo a pastagem tendo apresentado elevado teor de PB e DIVMO (Tabela 3) na avaliação inicial. Certamente os baixos ganhos obtidos nos pastejos iniciais são o reflexo do elevado teor de água presente nestas espécies (Tabela 1), que, apesar de apresentar excelente qualidade, não conseguem suprir os requerimentos desta categoria animal para a obtenção de elevados ganhos, pois a quantidade de MS ingerida pelos animais está ligada positiva e significativamente à porcentagem de MS da planta (COMERON, 1997) e a água presente nas células da forragem apresenta poder de enchimento, havendo limitação de consumo por falta de capacidade física.

Observa- se que na MTA o menor GMD foi obtido no primeiro período (489 g), ocorrendo aumento gradativo até atingir o valor máximo no terceiro período (832 g), que se manteve constante até o final do período de pastejo, já para o MAA e MTAA, houve redução no GMD do primeiro para o segundo período, aumentando nos períodos seguintes e chegando nos valores máximos no quarto período sendo, respectivamente, de 968 e $784 \mathrm{~g}$. A queda no GMD do primeiro para o segundo período, observada no MAA e MTAA, pode ser atribuída à diminuição mais acentuada na disponibilidade de forragem (Tabela 1), na DIVMO e no teor de PB (Tabela 3 ) da pastagem em relação ao MTA. O aumento no GMD da MTA do primeiro para o segundo período ocorreu, provavelmente, em função do baixo ganho de peso obtido no primeiro período e da menor variação na qualidade da pastagem. Na média de cada período, observa-se aumento no GMD do terceiro para o quarto período, mesmo com a queda na qualidade da pastagem como um todo. Neste período houve grande acúmulo de material morto que apresentou baixa qualidade e os animais em pastejo selecionam dieta de maior qualidade que a apresentada pelo resíduo.

A carga animal média (Tabela 5) durante a utilização da pastagem foi maior $(\mathrm{P}<0,05)$ na MTA em relação às demais, sendo de 1210, 1055 e $1116 \mathrm{~kg}$ de PV/ha, mostrando superioridade de 14,7 e 8,4\% em relação ao MAA e MTAA, respectivamente. Os valores encontrados são inferiores aos obtidos por RESTLE et al. (1998), no período de agosto a outubro, e superiores aos encontrados por CANTO et al. (1997). A carga animal na média das misturas teve redução significativa do primeiro para o terceiro período, ocorrendo queda de $13,06 \%$ na capacidade de suporte da pastagem, pois no momento do ajuste de carga (19/08) o resíduo estava relativamente baixo $(1383 \mathrm{~kg})$ e foi estimada taxa de acumulação inferior à taxa efetiva que ocorreu na pastagem, resultando, com isso, em aumento no resíduo, havendo a necessidade de elevação na carga animal em 91,28\% no período seguinte para controlá-lo, chegando na capacidade de suporte máxima no quarto período com $1668 \mathrm{~kg}$ de $\mathrm{PV} / \mathrm{ha}$.

Analisando as diferentes misturas, observa-se que a mistura triticale mais azevém apresentou menor oscilação na carga animal, constituindo-se ponto positivo para o manejo do complexo planta-animal,

Tabela 5 - Carga animal (kg PV/ha॰dia) por período e média do período experimental na pastagem com misturas de gramíneas anuais de estação fria ${ }^{1,2}$

Table 5 - Stocking rate ( $k g$ LW/ha•day) per period and over the experimental period in pasture in annual temperate grasses mixtures

\begin{tabular}{|c|c|c|c|c|c|c|}
\hline \multirow{2}{*}{$\begin{array}{l}\text { Tratamento } \\
\text { Treatment }\end{array}$} & \multicolumn{5}{|c|}{$\begin{array}{c}\text { Período } \\
\text { Period }\end{array}$} & \multirow[t]{2}{*}{$\begin{array}{l}\text { Média geral } \\
\text { Great mean }\end{array}$} \\
\hline & 10/06a $15 / 07$ & $15 / 07$ a $19 / 08$ & $19 / 08 \mathrm{a} 23 / 09$ & $23 / 09$ a $31 / 10$ & $31 / 10$ a $14 / 11$ & \\
\hline $\begin{array}{l}\mathrm{TR}+\mathrm{AZ} \\
T R+B Y\end{array}$ & 983 & 1103 & 1070 & 1653 & 1187 & $1210 \mathrm{~A}$ \\
\hline $\begin{array}{l}\mathrm{AV}+\mathrm{AZ} \\
O A+R Y\end{array}$ & 1030 & 770 & 629 & 1736 & 1043 & $1055 \mathrm{~B}$ \\
\hline $\begin{array}{l}\mathrm{TR}+\mathrm{AV}+\mathrm{AZ} \\
T R+O A+R Y\end{array}$ & 997 & 890 & 915 & 1616 & 1124 & 1116B \\
\hline $\begin{array}{l}\text { Média } \\
\text { Mean }\end{array}$ & $1003 c$ & $921 \mathrm{~cd}$ & $871 \mathrm{~d}$ & $1668 \mathrm{a}$ & $1118 b$ & \\
\hline
\end{tabular}

(Dia/mês, Day/month).

1 Médias, na linha, seguidas por letras diferentes (a, b, c, d) diferem $(P<0,05)$.

2 Médias, na coluna, seguidas por letras diferentes $(A, B)$ diferem $(P<0,05)$.

$3 \mathrm{TR}=$ triticale, $\mathrm{AV}=$ aveia, $\mathrm{AZ}=$ azevém.

1 Means, within a row, followed by different letters $(a, b, c, d)$ differ $(P<.05)$.

${ }^{3}$ Means, within a column, followed by different letters $(A, B)$ differ $(P<.05)$.

${ }^{3} \mathrm{TR}=$ triticale, $\mathrm{OA}=$ oat, $\mathrm{RY}=$ ryegrass. 
ocorrendo variação de $68,15 \%$ entre a carga mínima ( $1^{\circ}$ período) e a máxima ( $4^{\circ}$ período), já na mistura de aveia preta mais azevém ocorreu variação de $176 \%$ entre a carga mínima ( $3^{\circ}$ período) e a máxima $\left(4^{\circ}\right.$ período); a mistura com as três espécies apresentou comportamento intermediário, tendo variação de $81,6 \%$ entre a carga mínima ( $2^{\circ}$ período) e a carga máxima ( $4^{\circ}$ período). Este comportamento está diretamente relacionado à menor variação no resíduo e à melhor distribuição da produção de forragem. A pastagem é processo dinâmico influenciado por inúmeros fatores que carecem de informações sobre a distribuição da produção de forragem no período de utilização. A oscilação na capacidade de suporte da pastagem, que freqüentemente ocorre ao longo do período de utilização, devido à má distribuição na produção de forragem das espécies utilizadas em pastejo é decorrente, principalmente, das variações nas condições climáticas e da estacionalidade de produção das espécies utilizadas em pastejo. Isto constitui-se em um dos principais problemas enfrentados no manejo das pastagens, pois quando se deseja maximizar as produções de forragem e animal surge a necessidade de grande variação no número de animais necessário para ajustar a carga animal à produção de forragem.

O ganho de peso vivo por área (Tabela 6) está diretamente relacionado ao ganho médio diário e ao número de animais $\mathrm{x}$ dia/ha no período, e estes estão relacionados com a produção, a qualidade e o aproveitamento da forragem produzida. Verifica-se que a mistura triticale mais azevém apresentou ganho de peso vivo/ha 14,4 e 9,8\% superior à mistura de aveia preta mais azevém e a mistura das três espécies $(\mathrm{P}<0,05)$, sendo de 650,7; 568,8; e 592,4 kg de PV/ha, para MTA, MAA e MTAA, respectivamente. O ganho de peso vivo por ha na média das três misturas foi semelhante ao obtido por RESTLE et al. (1998), com a categoria terneiros, e superiores aos obtidos por QUADROS e MARASCHIN (1987), com terneiros de 10 a 12 meses de idade.

A eficiência de utilização da forragem encontrase na Tabela 7, na qual se observa que a melhor utilização ocorreu no MTAA, seguido pelo MTA e MAA, sendo, respectivamente, de 10,47, 12,72 e $14,62 \mathrm{~kg}$ de MS desaparecida por kg de PV produzido. A pior eficiência de utilização observada no MAA, provavelmente, ocorreu em conseqüência da maior quantidade de forragem perdida por pisoteio e senescência natural das plantas, uma vez que a qualidade da pastagem foi semelhante entre as misturas. Neste aspecto há necessidade de estudos que quantifiquem melhor as perdas de forragem que ocorrem ao longo do período de pastejo destas espécies, para se adotar manejo adequado para cada mistura, visando aumentar a eficiência de utilização da forragem produzida e tornando os sistemas de produção animal mais produtivos.

$\mathrm{Na}$ Tabela 8 encontram-se os custos, o benefício e o lucro obtido nas diferentes misturas. Observa-se que os custos fixos ( $\mathrm{R} \$ / \mathrm{ha}$ ) para as três misturas foram de 281,27 , tendo pequena variação nos custos pertinentes aos tratamentos, sendo que o custo total foi de $\mathrm{R} \$ 320,42 ; 312,69$; e 316,47 por hectare, para o MTA, MAA e MTAA, respectivamente. O benefício

Tabela 6 - Ganho de peso vivo (kg/ha) e por período e total, conforme as misturas de gramíneas anuais de estação fria ${ }^{1,2}$ Table 6 - Live weight gain (kg/ha) per period and total, according to the annual temperate grasses

\begin{tabular}{|c|c|c|c|c|c|c|}
\hline \multirow{2}{*}{$\begin{array}{l}\text { Tratamento } 3 \\
\text { Treatment }\end{array}$} & \multicolumn{5}{|c|}{$\begin{array}{l}\text { Período } \\
\text { Period }\end{array}$} & \multirow[t]{2}{*}{ Total } \\
\hline & 10/06a 15/07 & $15 / 07$ a $19 / 08$ & $19 / 08$ a $23 / 09$ & $23 / 09$ a $31 / 10$ & $31 / 10$ a $14 / 11$ & \\
\hline $\begin{array}{l}\mathrm{TR}+\mathrm{AZ} \\
T R+R Y\end{array}$ & 103,4 & 127,9 & 159,0 & 208,6 & 51,8 & $650,7 \mathrm{~A}$ \\
\hline $\begin{array}{l}\mathrm{AV}+\mathrm{AZ} \\
O A+R Y\end{array}$ & 142,3 & 59,7 & 82,6 & 246,0 & 38,2 & $568,8 \mathrm{~B}$ \\
\hline $\begin{array}{l}\mathrm{TR}+\mathrm{AV}+\mathrm{AZ} \\
T R+O A+R Y\end{array}$ & 132,0 & 76,1 & 127,4 & 205,0 & 51,9 & $592,4 \mathrm{~B}$ \\
\hline $\begin{array}{l}\text { Média } \\
\text { Mean }\end{array}$ & $125,9 b$ & $87,9 \mathrm{c}$ & $123,0 \mathrm{~b}$ & $219,9 \mathrm{a}$ & $47,3 \mathrm{~d}$ & \\
\hline
\end{tabular}

(Dia/mês, Day/month).

1 Médias, na linha, seguidas por letras diferentes $(a, b, c, d)$ diferem $(P<0,05)$.

2 Médias, na coluna, seguidas por letras diferentes $(A, B)$ diferem $(P<0,05)$.

$3 \mathrm{TR}=$ triticale, $\mathrm{AV}=$ aveia, $\mathrm{AZ}=$ azevém.

1 Means, within a row, followed by different letters $(a, b, c, d)$ differ $(P<.05)$.

${ }^{3}$ Means, within a column, followed by different letters $(A, B)$ differ $(P<.05)$.

${ }^{3} \mathrm{TR}=$ triticale, $O A=$ oat, $R Y=$ ryegrass. 
RESTLE et al.

Tabela 7 - Eficiência de utilização da forragem produzida em ganho de peso vivo por hectare na pastagem com misturas de gramíneas anuais de estação fria

Table 7 - Efficiency of transformation of the forage produced in live weight gain (LWG)/ha of pastures of annual temperate grasses mixtures

\begin{tabular}{|c|c|c|c|c|c|}
\hline $\begin{array}{l}\text { Tratamento } \\
\text { Treatment }\end{array}$ & $\begin{array}{l}\text { Prod. forragem } \\
\text { (kg MS/ha) } \\
\text { Forrage production } \\
\quad(\mathrm{kg} \mathrm{DM} / \mathrm{ha}) \\
\end{array}$ & $\begin{array}{l}\text { Resíduo final } \\
\text { (kg de MS/ha) } \\
\text { Final residue } \\
\text { (kg DM/ha) }\end{array}$ & $\begin{array}{c}\text { Forragem desaparecida } \\
\text { (kg MS/ha) } \\
\text { Disappeared forage } \\
(\mathrm{kg} \mathrm{DM/ha)}\end{array}$ & $\begin{array}{l}\text { GanhoPV } \\
(\mathrm{kg} / \mathrm{ha}) \\
\text { LW gain } \\
(\mathrm{kg} / \mathrm{ha}) \\
\end{array}$ & $\begin{array}{c}\text { Eficiência } \\
\text { (kg MS Prod/kg GPV) } \\
\text { Efficiency } \\
(\mathrm{kg} \mathrm{DM} \mathrm{Prod} / \mathrm{kg} \mathrm{LWG}) \\
\end{array}$ \\
\hline $\begin{array}{l}\mathrm{TR}+\mathrm{AZ} \\
T R+R Y\end{array}$ & 9696 & 1420 & 8276 & 650,7 & 12,72 \\
\hline $\begin{array}{l}\mathrm{AV}+\mathrm{AZ} \\
O A+R Y\end{array}$ & 10273 & 1955 & 8318 & 568,8 & 14,62 \\
\hline $\begin{array}{l}\mathrm{TR}+\mathrm{AV}+\mathrm{AZ} \\
T R+O A+R Y\end{array}$ & 8041 & 1836 & 6205 & 592,4 & 10,47 \\
\hline
\end{tabular}

$1 \mathrm{TR}=$ triticale, $\mathrm{AV}=$ aveia, $\mathrm{AZ}=$ azevém.

${ }^{1} T R=$ triticale, $O A=$ oat, $R Y=$ ryegrass.

Tabela 8 - Custo total, benefício e receita líquida $(R \$)$ na pastagem com misturas de gramíneas anuais de estação fria

Table 8 - Total cost, benefit and net income $(R \$)$ of pasture of annual temperate grasses mixtures

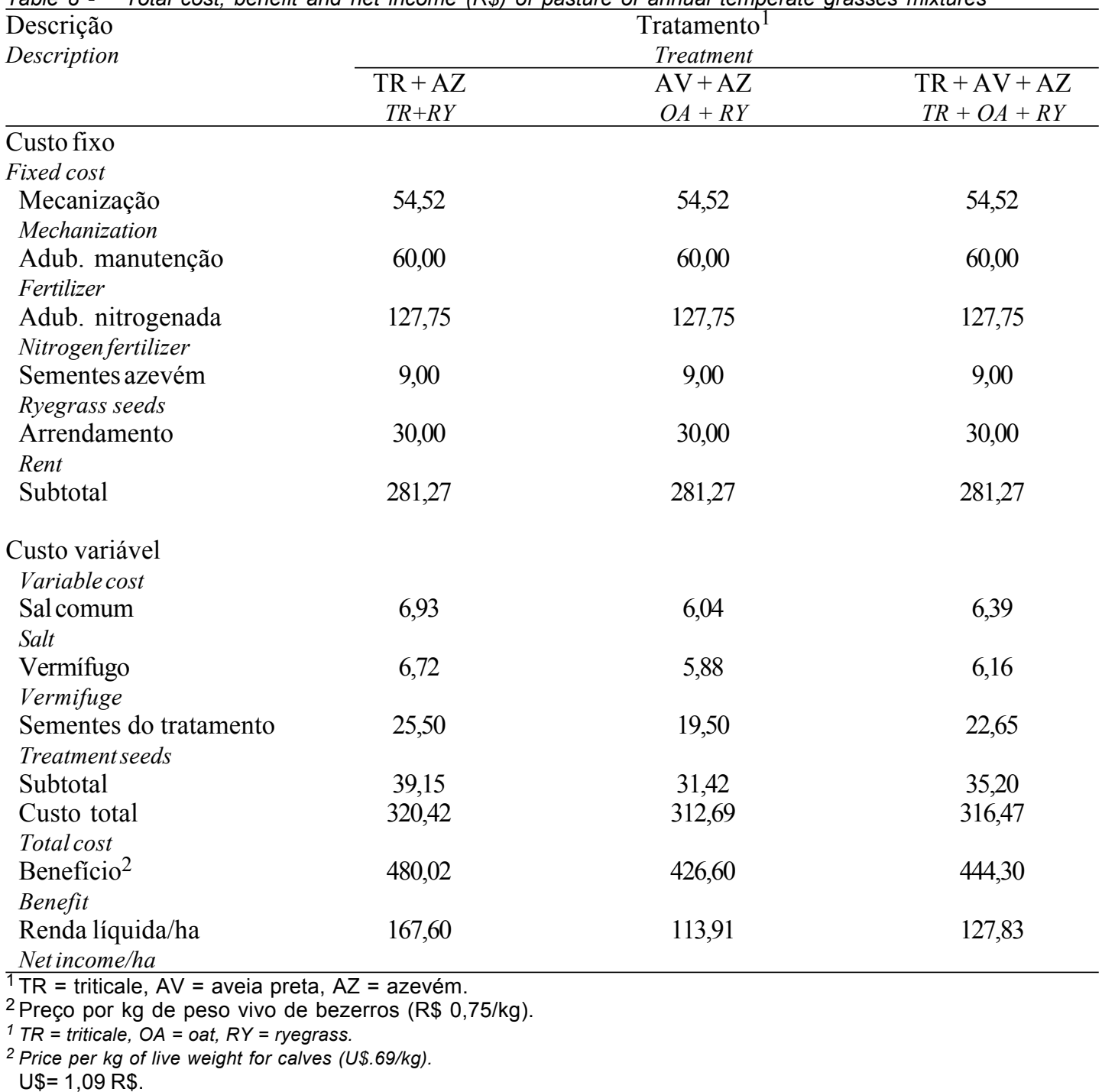


está diretamente relacionado com o ganho de $\mathrm{PV} /$ ha e com o preço pago pelo $\mathrm{kg}$ de $\mathrm{PV}$; foram obtidos valores de 480,02; 426,60; e 444,30 R \$/ha, o retorno do capital investido foi de 52,$3 ; 36,4$; e $40,4 \%$ e a receita líquida (R\$/ha) obtida foi maior na MTA $(167,60)$, seguido pela MTAA $(127,83)$ e MAA $(113,91)$.

\section{Conclusões}

O ganho médio diário dos animais foi semelhante entre as misturas.

A mistura triticale mais azevém apresentou menor variação na carga animal ao longo do período de pastejo e o maior ganho de peso vivo por hectare.

O maior custo, benefício, lucro e retorno do capital investido foram obtidos na mistura triticale mais azevém, seguido pela mistura triticale mais aveia preta mais azevém e aveia preta mais azevém.

\section{Referências Bibliográficas}

ASSOCIATION OF OFFICIAL ANALYTICAL CHEMISTS AOAC. 1984. Official methods of analysis. $14 \mathrm{ed}$ Washington. $1141 \mathrm{p}$.

BAIER, A.C. Triticale. In: BAIER, A.C., AUDE, M.I.S., FLOSS, E.L. As lavouras de inverno-1. São Paulo: Globo, 1989.p.76-106.

BAIER, A.C., NEDEL, J.L. 1985. Potencial do triticale no Brasil. Pesq. Agropec. Bras., 20(1):57-67.

BLASER, R.E. Manejo do complexo pastagem-animal para avaliação de plantas e desenvolvimento de sistemas de produçaõ de forragens. In: PASTAGENS. Piracicaba: FEALQ, 1990. 205p. p. 157-205.

CANTO, M.W., RESTLE, J., QUADROS, F.L.F. et al. 1997. Produção animal em pastagem de aveia (Avena strigosa Schreb) adubada com nitrogênio ou em mistura com ervilhaca (Vicia sativa L.). R. Bras. Zootec., 26(2):396-402.

COMERON, E.A. 1997. Efectos de la calidad de los forrajes y la suplementacion en el desempeño de ruminantes en pastoreo (con especial referencia a vacas lecheras) In: SIMPÓSIO SOBRE AVALIAÇÃO DE PASTAGENS COM ANIMAIS, 1997, Maringá. Anais... Maringá: Clóvis Cabreira Jobim, Geraldo Tadeu dos Santos e Ulysses Cecato (eds.) 149 p. p.
53-73.

IBGE - Instituto Brasileiro de Geografia e Estatística. 1996. Anuário Estatístico do Brasil, Rio de Janeiro, v. 56.

LUPATINI, G.C., RESTLE, J., CERETTA, M. etal. 1998. Avaliação da mistura de aveia preta (Avena strigosa) e azevém (Lolium multiflorum) sob pastejo submetida a níveis de nitrogênio. I Produção e qualidade de forragem. Pesq. Agropec. Bras. (prelo).

MORENO, J.A. 1961. Clima do Rio Grande do Sul. Porto Alegre: Secretaria da Agricultura. 41p.

MORAES, A. de. Produtividade animal e dinâmica de uma pastagem de pangola (Digitaria decumbens), azevém (Lolium multiflorum) e trevo branco (Trifolium repens), submetida a diferentes pressões de pastejo. Porto Alegre: UFRGS, 1991. 200p. Tese (Doutorado em Zootecnia) - Faculdade de Agronomia da Universidade Federal do Rio Grande do Sul.

MOTT, G.O., LUCAS, H.L. The design conduct and interpretation of grazing trials on cultivated and improved pastures. In: INTERNATIONAL GRASSLAND CONGRESS, 6, 1952. Proceedings... Pensylvania, State College Press., 1952. p.1380-1395.

QUADROS, F.L.F. de, MARASCHIN, G.E. 1987. Desempenho animal em misturas de espécies forrageiras de estação fria. Pesq. Agropec. Bras., 22(5):535-541.

RECOMENDAÇÕES DE ADUBAÇÃO E CALAGEM PARA OS ESTADOS DO RIO GRANDE DO SUL E SANTA CATARINA. 1989. 2. ed. Passo Fundo: SBCS, Núcleo Regional Sul - EMBRAPA- CNPT. 128 p.

RESTLE, J., LUPATINI, G.C., VALENTE, A.V. et al. Avaliação da mistura de aveia preta (Avena strigosa) e azevém (Lolium multiflorum) sob pastejo submetida a níveis de nitrogênio. IProdução animal. In: REUNIÃO ANUAL DA SOCIEDADE BRASILEIRA DE ZOOTECNIA, 30, 1993, Rio de Janeiro. Anais... Viçosa: SBZ, 1993. p.71.

RESTLE, J., LUPATINI, G.C., ROSO, C. et al. 1998. Eficiência e desempenho de diferentes categorias de bovinos de corte em pastagem cultivada. R. Bras. Zootec., 27(2):397-404.

SAS, Institute Inc. SAS Language reference. Version 6, Cary, NC: SAS Institute Inc., 1990.1042 p.

TILLEY, J.M.A., TERRY, R.A. 1963. A two- stage technique for the in vitro digestion of forage crop. J. Brit. Grassland Soc., 18(2):104-111.

Recebido em: 15/10/97

Aceito em: 06/10/98 